\title{
Multicultural Education: Teachers' Perceptions And Preparation
}

\author{
Sunita Sharma, (Email: SSharma@mail.nwmissouri.edu), Northwest Missouri State University
}

\begin{abstract}
In this study, the researcher has explored and described $K-12$ school teachers' perceptions of multicultural education and their professional preparation to teach culturally diverse students in a Northwest Florida school district. This was a descriptive study, combining quantitative and qualitative research methods. A proportionate stratified random sample of $150 \mathrm{~K}-12$ teachers was used for the survey and a case study of 15 teachers for the interviews. Correlation coefficients and ANOVA results determined overall significantly low correlations between teachers' demographics and their perceptions. Previous research and the findings from this study indicate a need for effective preparation in multicultural education for teachers of culturally diverse students.
\end{abstract}

\section{INTRODUCTION}

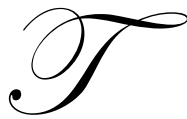

he United States of America has become a multicultural global village that experiences continual growth in cultural diversity. According to Gollnick and Chinn (1998), educators today are faced with an overwhelming challenge of teaching students from culturally diverse backgrounds in this multicultural global society. To work effectively with culturally diverse students in schools, teachers must understand the cultural backgrounds of students and cultural settings of the schools to be able to develop effective teaching and learning strategies.

\section{TEACHERS' PERCEPTIONS OF MULTICULTURAL EDUCATION}

Teachers' perceptions and attitudes about culturally diverse students in the nation's classrooms are the key factors in motivating, educating, and making a difference in the education of students irrespective of their gender, ethnicity, age, religion, language, or exceptionality. The majority of teachers usually, consciously or unconsciously, exhibit biases towards students in some manner. Often teachers' teaching styles are very different from the learning styles of culturally diverse students (Gollnick \& Chinn, 1991).

According to Gay (1994), teachers often perceive their values, beliefs, and actions as the standard norms, and what they know and what they teach is governed by educational principles of teaching. Due to the lack of understanding of ethnic, racial, social, and linguistic diversity of students, teachers can engage themselves consciously or unconsciously in "mis-education practices." Due to the failure on the part of teachers to understand, accept, and appreciate who these students are, students feel that the school environment is alien and hostile toward them. This situation causes stress, anxiety, and a feeling of a lack of support among students, which can affect students' daily academic performance. Learning in a school setting is high risk-taking activity for the majority of the culturally diverse students. All students, including culturally diverse students, work better when they feel that they are secure regarding who they are.

According to Costa (1997), formal education depends upon the attitudes and professional preparedness of teachers. It becomes all the more critical to have appropriate attitudes, perceptions and professional preparation to teach effectively in multicultural classrooms. Generally, teachers have a simplistic, romantic, and humanistic vision of multicultural education; this is not a realistic idea because this notion focuses only on external factors such as folklore. Pena (1997) noted that analyses, related to teachers' perceptions, indicate that educators spend little time getting to know their students and, therefore, have very little knowledge about them. At the same time, the students 
from the cultural minority groups experience rejection by their teachers because of their teachers' perceptions and lack of preparation to teach such students.

In formal situations, teachers knowingly deny the fact that the presence of cultural minority students causes problems. However, in informal conversations, these same teachers provide negative and conflicting stories about minority students. They complain that these students have language deficits for which the teachers have to compensate. In terms of training, teachers are very aware of the lack of their preparation in multicultural education, and yet some of these teachers do not consider training in multicultural education a high priority (Ladson-Billings, 1995).

Fumy and Bechtol (1999) investigated how teachers' perceptions influence classroom practices in three areas. Teachers have low expectations of linguistically diverse students in the areas of valuing bilingualism, readingrelated instructional practices, and reading-related assessment. Teachers with negative perceptions have a tendency to discourage linguistic minority students from using their primary language and rarely or never use bilingual materials or activities for academic purposes. Fueyo and Bechtol further state that teachers with negative perceptions of ethnic minorities have also exhibited differential treatment with students because of gender differences and stereotypical views on students' last names.

Gorski (2000) strongly emphasized that teachers have a dual responsibility to engage in the critical and continual process of examining their prejudices, biases, and perceptions that affect students' learning experiences. To be an effective multicultural educator and an effective instructor, a teacher must continue self-examination and transformation. Nelson (2001) argues that having a socially held belief system and valuing racial and cultural differences are the keys to improving equal opportunities for all students.

\section{PREPARING TEACHERS FOR THE MULTICULTURAL CLASSROOM}

"White Americans increasingly reject racial injustice in principle, but remain reluctant to accept the measures necessary to eliminate the injustice." (Pettigrew, 1979).

Futrell, Gomez, and Bedden (2003) state that cultural diversity in American society and classrooms pose a great challenge to educators and to administrators in higher education. Nationwide, fewer than $15 \%$ of teachers and fewer than $12 \%$ of the school administrators are from ethnic minority groups. Only $10.3 \%$ of the teachers in the U.S. are African-American. Hinchey (1994) reports that according the analysis of the teacher education population, 92\% of the teachers are Caucasians and 85\% are from the middle socio-economic class. Bell and Munn (2000) indicate that the average European- American teachers are about 40 years of age, married, and are parents of at least two children by the time they start teaching. According to Wallace (2001), $90 \%$ of preservice teachers are middle-class Caucasians and a significant number of them are the first generation to attend college. Thus, these teachers are not prepared to teach culturally diverse students effectively.

Nelson (2001) emphasizes that teacher education faculty are responsible for providing training and preparing the preservice teachers to enter the teaching profession with the ability and affinity to go beyond stereotypes associated with education and schooling, teaching, learning, and curriculum policies and practices. Bigler (2002) recommends that all teachers (preservice and inservice) need to be well trained in the history of race relations and educational anthropology in the U.S. to make the connection with educational outcomes.

Teaching effectively in a multicultural classroom requires culturally sensitive strategies and content to provide equal opportunities for academic success and individual growth of all students. The most effective teachers have learned to understand the cultures of students and their students trust them (Schlosser, 1992). Preservice teachers need to become reflective practitioners and learn to apply observational, empirical, and analytical skills to monitor, evaluate, and revise their own teaching styles. They need to develop an awareness of their own cultural perspectives, beliefs and behaviors and to be aware that their own cultural perspective is not the universal perspective and the only right one. Preservice teachers need to acquire multicultural competence, the ability to be functional in cross-cultural 
settings, and be able to interact and communicate effectively with culturally diverse students and their parents (Chisholm, 1994).

Until 1960, the majority of immigrants to the U.S. came from Europe. Between 1980 through 2002, the majority of immigrants have come from Asia, Central America, and the Caribbean. Additionally, large numbers of Puerto Ricans and Mexican- Americans are the fastest growing ethnic groups in America today. By the year 2050, descendants of all nonwhite groups are expected to represent about $40 \%$ of the American population (Parla, 1994). According to the U.S. Department of Education (1990), Office for Educational Research indicated that between 1979 and 1989, the number of non- English speaking children between the ages of 8 and 15 increased by $41 \%$. It is evident that the number of Limited English Proficient (LEP) students and culturally diverse students is on the rise. At the same time, there is a lack of specialized multicultural training for U.S. classroom teachers (Pallas, Natiello, \& McDill, 1989).

Blackwell, Futrell and Imig (2003) stress that the turn of the 21st century has brought in a larger number of immigrants along with a greater diversity and a greater challenge for the education system. It has become imperative to stress diversity through multicultural education. To support diversity through multicultural education, some significant changes in the curriculum of teacher education are needed. Blackwell et al. Stress the need to include courses related to culture, linguistics, diversity, gender, race, equity, and power in the teacher education curriculum to empower new teachers to work against the social and structural arrangements in schools and society that promote inequality.

Parla (1994) proposed three major components to prepare all teachers to instruct culturally diverse and limited English proficient students. These three components are (a) theoretical base, (b) linguistic and cultural diversity base, and (c) experimental base. The theoretical base establishes the foundation of common definitions, knowledge of issues, and self-identity upon which the trainee can build the skills to implement effectively a multicultural program. The linguistic and cultural diversity base provides the trainee with needed competencies in second language acquisition and development, knowledge of the relationship between language and culture, and an increased ability to affirm the cultures of diverse students. Cultural diversity awareness is needed to provide trainees with the knowledge of and experience with a variety of racial and ethnic groups in the U.S. Limited or no experience with culturally and linguistically diverse groups in their own communities makes it more difficult for teachers to accept and affirm diversity as a part of the American mosaic.

Fueyo and Bechtol (1999) recommend that in order to have instructional effectiveness in a culturally diverse classroom, teachers need to respect cultural differences and diversity; the teachers need to be culturally aware and competent and able and willing to incorporate students' cultures into their classroom curriculum and modify instruction for the success of culturally diverse students.

According to Parla (1994), the experimental base enables teacher trainees to receive practical and hands-on experience with students. For the success of the trainees in field training, it is important that the supervising teachers are trained to become mentors in the field of multicultural education. Prospective mentors must be provided training with staff development activities to ensure their effective mentorship. Otherwise, the validity of the field training remains questionable.

Costa (1997) recommends that it is necessary to approach teacher training from moral and attitudinal perspectives, along with the understanding of the implications of multicultural education from educational, methodological, and political positions. It is also necessary to include cultural diversity of students as one of the objectives of progressive education for diversity. Costa further emphasizes that teacher training should be a commitment to the present and future, and not to the past.

Penny, Forney, and Harlee (2000) report that Florida was one of the first states to make multicultural education courses mandatory for teacher certification during the 1970s. However, teachers still lack sufficient training and resources for implementing relevant multicultural curriculum, such as the use of intervention strategies, trained school staff, and professionals from diverse backgrounds, for the successful implementation of multicultural 
education. Penny et al. state that many teachers around the country have not taken a single course in multicultural education, and those who have taken one or more courses in multicultural education are not using the knowledge in their instruction. Teachers need to understand that multicultural education provides access for enhancing the quality of education by capitalizing on all human resources.

Gay (1994) and Ladson-Billings (1994, 1995) suggest that the teacher education curriculum must develop a theoretical and practical connection between cultural relevance and the academic success of culturally diverse students. Those authors also recommend that teacher education faculty should plan to integrate diversity education in to all aspects of a teacher education curriculum. The teacher education curriculum should also provide preservice teachers with practical experience, an opportunity to learn to apply diversity education and training. Munn (1996) suggests that teacher education faculty at the colleges and universities should be appropriately trained in cultural diversity education to be able to teach preservice teachers to be culturally sensitive.

Zeichner (1993) recommends several elements for educating teachers to be able to teach culturally diverse students effectively. Preservice teachers should be interviewed before they are accepted in the teacher education program on their sensitivity of cultural diversity. During the teacher training program, preservice teachers should be taught to examine their attitudes toward other ethnic groups, prejudice, racism, and socioeconomic disparities, and how to deal with these issues in the classroom. Zeichner further asserts that preservice teachers should be taught how to learn about students' learning styles, use instructional strategies, and employ assessment procedures sensitive to their cultural and linguistic backgrounds. Student teachers should have field experience with adults and children of diverse ethnic groups with guided reflections.

Wallace (2001) emphasizes the need of multicultural education in the mainstream course work for preservice teachers to be able to understand the experiences and developmental needs of culturally diverse students. Preservice teachers need to involve themselves in critical reflection of their own social location and learn to appreciate cultural diversity in the community and schools. It is imperative for universities to provide opportunities and role models for preservice teachers to think about and discuss cultural diversity.

According to Penny et al. (2000), it is very crucial, presently, for the teachers to learn how to be able to adapt to the constantly changing teaching environment. According to Grant, as cited in Penny et al., "there are nine principles that educators need to follow in order to provide multicultural education to the changing demographics of a multicultural society:

1. It must help students increase their academic achievement levels in all areas, including basic skills, through the use of teaching approaches and materials that are sensitive and relevant to students' sociocultural background and experiences.

2. Attention to voice must be a part of multicultural instruction.

3. Verbal and non-verbal communication patterns between students and teachers must be analyzed to increase the involvement of students in the learning process.

4. The learning styles of students and teaching style of teachers must be understood and used to develop effective instructional strategies.

5. Multicultural education must permeate the formal curriculum.

6. Multicultural education must impact the hidden curriculum at all levels.

7. Multicultural education must teach students to think critically by allowing them the freedom to ask questions and develop the tools to reason.

8. Multicultural education requires an understanding of the culture of families' in the community.

9. Multicultural education must use the community as a resource" (p. 220).

Merryfield (1995) emphasized that global knowledge and cross-culture experience must be infused throughout teacher education programs. Field experience and internships should be structured where the preservice teachers can work with talented multicultural education instructors. Multicultural education develops the knowledge, skills, attitudes, and the basis for decision making and participation in a nation characterized by cultural pluralism, interconnectedness, and international economic competition. According to Marriott (2003), in addition to training 
preservice teachers in multicultural education, new teachers must be provided with the access to a trained partner, a mentor to assist in clarifying educational goals and challenges of educational curriculum.

Merryfield (1995) argues that educators need to be aware of the complexities of globalization and develop skills in multicultural education if they really want to become effective citizens and teachers in a pluralistic and interdependent world. Gorski (2000) recommends that educators, researchers, activists, and everyone else must continue to practice and apply multicultual education inside and outside of the classroom. Finally, all teachers must be trained in multicultural education to be able to provide effective instruction for the ever-changing, increasingly diverse student population. Linguistic diversity, among other elements, must be acknowledged as an important component of multicultural education (Parla, 1994). Linguistic diversity is not a matter of individual preference, curricular accessory, or an academic whim. It should not be an "added-on" course after providing for rudimentary knowledge and skills. Multicultural education is not merely an ethnic issue. It is everyone's issue, for teaching is a multicultural Experience (Chisholm, 1994).

\section{PURPOSE OF THE STUDY}

The major question guiding this study was how do teachers perceive their preparation to teach culturally diverse students? The purpose of this study was to explore and describe a selected group of high school, middle school, and elementary school teachers' perceptions concerning their professional preparation to teach culturally diverse students and to solicit their recommendations for training in the field of teacher education preparation programs.

\section{SIGNIFICANCE OF THE STUDY}

This study is significant in three ways. First, it is important because it provides teacher education programs with recommendations for a contemporary preservice teacher training curriculum. This study provides data that document teachers' perceptions of where and how they acquired and developed their skills to teach diverse student populations. Teachers were asked to share their academic and personal demographic information and explore their perceptions about multicultural education. Findings of this study can inform teacher educators about the type of experiences that could be incorporated in teacher education programs to help sensitize students to cultural diversity (Howell, 1997).

Second, the focus of this study is on teachers' perceptions of multicultural education and teacher preparation. The recommendations and suggestions provided by the participants could benefit the teacher education programs at colleges and universities because many teacher education programs are struggling with how to prepare prospective teachers to be effective instructors in culturally diverse classrooms. Some insights on teaching beyond the geographical limits of the study are provided here

Third, this study is significant because it is the first school district-wide survey of public school teachers in Escambia County, Florida, that investigates teachers' perceptions of multicultural education and their professional preparation in teaching culturally diverse students.

\section{RESEARCH QUESTIONS}

Drawing upon the issues and concerns addressed in the literature on teacher preparation to teach culturally diverse students, this researcher asked selected group of high school, middle school, and elementary school teachers in The School District of Escambia County, Florida to assess their perceptions concerning their professional preparation to teach culturally diverse students. This researcher also asked teachers to offer recommendations for teacher education preparation in teaching culturally diverse students. Thus, a survey was conducted to address the following questions: 
1. What are the teachers' demographic characteristics?

2. What are the teachers' perceptions concerning their professional preparation to teach culturally diverse students?

3. What relationships exist between teachers' perceptions concerning their professional preparation to teach culturally diverse students and the following demographic characteristics?

a. Ethnicity of teachers, b.Educational level, c.Years of teaching experience,

d. Current grade level taught, e.Contact with culturally diverse students, and

f. Number of semester hour credits in multicultural education taken.

4. With regard to methodology of teaching culturally diverse students, what suggestions are offered by the teachers (participants) for inclusion in college and university teacher education preparation programs?

5. What responses do practicing classroom teachers provide when administered personal interviews on the following nine questions about the significance and challenges of multicultural education?

a. What is the meaning of multicultural education?

b. What is your perception of multicultural education?

c. What kind of personal experiences have affected your perception of teaching culturally diverse students?

d. What kind of professional experiences have affected your perception of teaching culturally diverse students?

d. How do you perceive and deal with the prejudices of culturally diverse students?

e. How do you perceive that your teacher education program has prepared you to teach effectively in a culturally diverse classroom?

f. What do you think is the significance of multicultural education?

g. What do you perceive as the challenges of multicultural education?

h. What recommendations would you suggest to college and university teacher education programs to prepare future teachers to teach culturally diverse students?

\section{METHODOLOGY}

Qualitative and quantitative research techniques were utilized in this study. Data were gathered using a questionnaire survey and a case study. The target population was public high school, middle school and elementary school teachers from The School District of Escambia County, Florida. Fifty teachers from each educational level were selected using a proportionate stratified random sample. The questionnaire was mailed to the selected teachers with a pre-self-addressed stamped return envelope. For the case study (interviews) 15 teachers were selected. Five teachers from each educational level (high school, middle school, and elementary school) were selected using a proportionate stratified random sample from the same population used for the questionnaire survey.

\section{Statistical Analysis}

For Part I, on the demographic characteristics of participants such as gender, ethnicity, age, education, and years of teaching experience, grade level of student teaching, subject taught, income, significant contact with culturally diverse people, and credit courses in multicultural education questionnaire, the data were reported using descriptive statistics consisting of frequencies, percentages, and measures of central tendency. Standard deviations were used to measure variability. For Part II, on teachers' preparation and perceptions of multicultural education questionnaire, which consisted of 23 statements, descriptive statistics were used to report overall responses to the statements.

Part III consisted of one open-ended question on personal comments and suggestions on teacher education preparation programs for instructing culturally diverse students. The answers to this question were organized into discreet categories. A count was conducted on the number of the respondents who shared comments in one or more categories regarding their perceptions about professional preparation to teach culturally diverse students. These categories were operationally defined. Patterns of similar comments were identified as emergent themes and several examples of responses were cited for each category 


\section{Case Study (Interviews)}

According to LeCompte and Preissle (1993), "case studies can be qualitative as well as quantitative. In the term case study, a case is the number of units one studies. Case study analysis is appropriate for intensive, in-depth examination of one or few aspects of a given phenomenon" (pp. 32-33). In this study, the purpose of the case study (interviews) was to gather qualitative supplemental data with maximum efficiency and minimum bias regarding the teachers' perceptions of multicultural education and their professional preparation to teach a culturally diverse student population. These interviews allowed the interviewees to provide detailed accounts on the topic at issue. Interviews provide immediate feedback, permit the interviewee to follow up on leads, and obtain additional data to enhance clarity (Tuckman, 1999).

Interviews were conducted with 15 participants: 5 high school teachers, 5 middle school teachers, and 5 elementary school teachers. Participants were selected by proportionate stratified random sampling methodology from the same sample which was used for the questionnaire survey. Each of the participants was assigned a code number. Once the interviewees were selected, the researcher worked out a mutually convenient interview schedule with the interviewees. Interviews were conducted one-on-one in neutral and mutually convenient settings. Each interview lasted for approximately 30 to 45 minutes as was estimated. Interviews were audio taped with the permission of the interviewees and later transcribed. The use of tape recorders has several advantages in recording the interview data for research. It reduces the tendency of interviewers to make an unconscious selection of data favoring their biases and it is also possible to reanalyze the taped interview data to test hypotheses not considered in the original study. With tape-recorded data, it is possible for a person other than the interviewer to evaluate, classify, and score the responses. Tape recording allows calculation of a reliability coefficient on the obtained interview data (Borg \& Gall, 1989).

\section{SUMMARY, DISCUSSION, AND RECOMMENDATIONS}

The focus of the current research was the topic of teacher preparation in teaching culturally diverse students in our nation's school system. Studying teachers' perceptions concerning their professional preparation to work with culturally diverse students assist the teacher education programs to prepare teachers to work more effectively with culturally diverse students.

Five categories were identified from these data. The highest frequency of responses was recommendation for more credit courses at the university in multicultural education and inclusion of multicultural topics in other courses as well. The second highest frequency of responses was recommendation for in-service workshops. The third highest frequency of responses was recommendation for teachers for real-life experiences with culturally diverse people. The fourth highest frequency of responses was in the category of general comments about multicultural education. In this category, participants suggested education abroad for real-life experience in developing and third world countries. The lowest frequency of responses was the recommendation for changes in overall teacher education programs at the university level.

Respondents seemed to have serious concerns about the need for training and experience in multicultural education for teachers in culturally diverse classrooms. The majority of the respondents commented on more than one category, emphasizing the need for training in multicultural education for teachers.

What responses do practicing classroom teachers provide when administered personal interviews on the nine questions about significance and challenges of multicultural education? After transcribing the interviews from audiotape onto paper, the researcher drew conclusions for each of the nine questions answered by the 15 respondents. During interviews, teachers quite openly shared their feelings whether or not they were professionally prepared to teach culturally diverse students. Teachers also made strong recommendations suggesting a variety of options for training practicing teachers and preservice teachers in multicultural education. The recommendations were (a) more courses in multicultural education; (b) infusion of multicultural education in across the curriculum at the university; () practicum in culturally diverse classrooms; (d) inservice workshops, seminars and presentations for practicing teachers. Some of the teachers even recommended teachers study abroad in developing and underdeveloped countries. 


\section{IMPLICATIONS}

From the literature review and current findings, four major implications have emerged. These are (a) implications regarding instruments used to assess teachers' perceptions, (b) implications related to gender, (c) implications related to ethnicity, and (d) implications related to leadership and professional preparation for successful multicultural teacher education program.

\section{Implications Regarding Instruments Used to Assess Teachers' Perceptions}

The researcher used quantitative and qualitative methods. A survey and a case study (interviews) were used to collect data for this study with a $96 \%$ response rate on the survey. It is quite interesting to note how participants responded differently on the survey and in the interviews. The researcher concluded from the findings that respondents probably took the 23 items of the questionnaire as a test-taking task and responded thoughtfully. Such data reflect what is inside a respondent's mind, but data can be influenced by both self-awareness and desire to create a favorable impression (Tuckman, 1999). The scores on this section indicate that the respondents were in high agreement as to their professional preparation to teach culturally diverse students.

Contradictions were found when participants responded differently to the survey and to the open-ended Question 4 and during the interviews to Question 5. According to Johnson (1998), it is quite likely that the formats of open-ended questions and interviews might elicit responses that arouse feelings and emotions. Writing responses or talking face-to-face is quite like recalling images, emotions, and episodic perceptions that reflect personal ideologies. The researcher has recommended an in-depth study to explain the discrepancies between the qualitative and quantitative findings in this study.

\section{Implications Related to Gender}

The findings of this study indicated overrepresentation of females with $75 \%$ response rate, as is true of the profession. Particularly, female teachers outnumber male teachers in K-12 grades (Johnson, 1998). Is it possible that males consider themselves less competent or overly competent to be teachers and consider teaching to be a female job? This implication suggests further investigation as to why there are more female than male teachers in the K-12 grade schools.

\section{Implication Related to Ethnicity}

Findings indicated that $86.1 \%$ of the respondents were Caucasians, $6.3 \%$ were African-Americans and few respondents were from other ethnicities. The literature review in this study indicates that there is a significant increase in number of other ethnic groups other than African-Americans in U.S. schools every year. However, there is no increase in the number of teachers from diverse cultural backgrounds. The findings suggest the need for further investigation into the reasons why there is a lack of proportionate representation of diverse ethnic groups in the teaching profession. The researcher suggests finding ways to encourage people of diverse ethnic backgrounds into the teaching profession.

\section{Implications of Leadership and Professional Preparation for Successful Multicultural Teacher Education Programs}

The literature review and the findings of this study indicate that universities are not operating from a comprehensive multicultural perspective with regard to teacher preparation programs. Universities and school districts nationwide need to mutually agree upon the definition of multicultural education. University faculties should be culturally diverse to demonstrate how multicultural education and cultural diversity can be effectively incorporated into the curriculum and into the general school environment. 


\section{RECOMMENDATIONS}

\section{Recommendations for More Credit Courses in Multicultural Education}

The majority of the respondents to the open-ended Question 4 and case study (interviews) in question 5 strongly recommended more courses in multicultural education, and the inclusion of multicultural topics in other courses. Due to a large influx of culturally and linguistically diverse people in the U.S. in general and in Northwest Florida in particular, it has become imperative that our teachers are well trained to teach culturally diverse students effectively.

\section{Recommendations for Inservice Workshops in Multicultural Education}

The majority of teachers have very little or no training in multicultural education. Intensive on-going training and professional development through workshops, seminars, cultural exchange programs, visits and study in socially and culturally different countries for teachers are recommended.

\section{Recommendations for Pre-service and In-service Teachers for Real-Life Experiences with Culturally Diverse People}

Volunteering in culturally diverse communities, socializing to understand culturally diverse people with an open mind, and travel to developing and under- developed countries are recommended as worthwhile goals.

\section{Recommendations For Future Research} education.

This researcher recommends a number of topics for further study for the advancement of multicultural

1. Similar research studies in the area of teachers' perceptions of professional preparation to teach culturally diverse students should be replicated at several school districts in the country in order to compare and contrast the findings with those of this study.

2. Conduct an in-depth study to find out why participants respond differently to survey and open-ended questions and face-to-face interviews.

3. In future research, investigators should observe the teachers in their classrooms for their teaching strategies, techniques, and learning environment and compare these with their responses to surveys and interviews. This might provide the researcher more accurate data to test the rhetoric against the practice (Howell, 1997).

4. The literature review for this study indicates that there is a significant increase of culturally diverse minority people in other professions in this country. The researcher recommends a study to find out why these minorities do not opt for the teaching profession and what can be done to encourage the members of culturally diverse minorities to choose the teaching profession

5. Further research needs to be conducted to find the reasons why there are significantly fewer male teachers as compared to female teachers in the U.S. schools.

6. Findings from the interviews with the participants indicated that the majority of them grew up and went to public schools in Northwest Florida. The majority of teachers also graduated from the University of West Florida's teacher education program. A study is needed to investigate what other universities are offering in the teacher education programs to prepare inservice and preservice teachers to teach effectively in culturally diverse classrooms.

Finally, Banks and Banks (1995) intimated that research studies on teacher education programs that focus on multicultural education are quite limited. Multicultural teacher education occupies a critical position between multicultural theory and multicultural practice. Banks and Banks further cautioned that it is time for multicultural teacher education to assume a proactive leadership role or risk a marginalization that will have dire consequences for the fate of our teachers, our schools, and our nation. 


\section{REFERENCES}

1. $\quad$ Banks, J. A. \& Banks, C.A.M. (Eds.), (1995), Handbook of research on multicultural education, New York: Macmillan.

2. $\quad$ Bell, E. D., \& Munn, G. C., (2000), “Can we create dreamkeepers for diverse classrooms?” (Electronic version), National Forum Journals, 8, 2-9.

3. Bigler, E., (2002), White teachers, race matters: "Preparing teachers for the new millennium" (Electronic version), Electronic Magazine of Multicultural Education, 4, 1-10.

4. Blackwell, P. J., Futrell, M. H., \& Imig, D. G, (2003). "Burnt water paradoxes of schools of education", Phi Delta Kappan, 84, 356-361.

5. $\quad$ Borg, W. R. \& Gall, M. D., (1989), Educational research: An introduction, New York: Pitman.

6. Chisholm, I. M., (1994), "Preparing teachers for multicultural classrooms". The Journal of Education Issues of Language Minority Students, 14, 43-68.

7. Costa, X. B., (1997), Intercultural education: Theories, policies and practices, Brookfield, Vermont: Ashgate.

8. Fueyo, V., \& Bechtol, S.,(1999), "Those who can teach: Reflecting on teaching diverse populations", Teacher Education Quarterly, 26, 1-10.

9. Futrell, M. H., Gomez, J., \& Bedden, D., (2003), "Teaching the children of a new America: The challenge of diversity", Phi Delta Kappan, 84, 381-385.

10. Gay. G., (1994), “A synthesis of scholarship in multicultural education”, (Urban Monograph No. RI88062012), Oak Brook, Illinois, North Central Regional Educational Laboratory.

11. Gollnick D. M., \& Chinn, P. C., (1991), "Multicultural education for exceptional children”, ERIC Digest \# 498, retrieved June 22, 2002 from http://www.ed.gov/databases/ERIC_Digests/ed333620.html.

12. Gorski, P., (2000), "The challenge of defining a single 'multicultural education"', Multicultural education, retrieved February 3, 2002 from http://www.mhhe.com/socinece/education/multi/define.html.

13. Hinchey, P. H., (1994), "Introducing diversity: We don't have to wait for a program", Action in Teacher Education, 16, 28-36.

14. Howell, M. H., (1997), "Multicultural teacher preparation: Experiences that affect the perceptions and behaviors of teachers in their ability to embrace diversity", unpublished doctoral dissertation, University of Massachusetts Amherst.

15. Johnson, G. G., (1998), “Teachers' beliefs about being professionally prepared to teach culturally diverse students", unpublished doctoral dissertation, The Ohio State University.

16. Ladson-Billing, G., (1994), The dream keepers: Successful teachers of African-American children, San Francisco: Jossey-Bass.

17. Ladson-Billing, G., (1995), “Toward a theory of culturally relevant pedagogy”, American Educational Research Journal, 32, 670-674.

18. LeCompte, M. D. \& Preissle, J., (1993), Ethnography and qualitative educational research. $\left(2^{\text {nd }}\right.$ Ed.), San Diego, California: Academic Press.

19. Marriott, D. M., (2003), "Ending the silence", Phi Delta Kappan, 84, 496-497.

20. Merryfield, M., (1995), "Teacher education in global and international education", ERIC Clearinghouse on Teaching and Teacher Education, Washington, DC, (ERIC Document Reproduction Serial No. ED384601).

21. Munn, G. C., (1996), "Preparing teachers for a culturally diverse classroom: Multicultural Education for preservice teachers", unpublished doctoral dissertation, East Carolina University, Greenville, North Carolina.

22. Nelson, T., (2001), "Editor's Introduction: Advancing educational opportunities in a multicultural society", Teacher Education Quarterly, 26(3), 147-156.

23. Pallas. A. M., Natiello, G,, \& McDill, E. L., (1989), "The changing nature of the disadvantaged population: Current dimensions and future trends", Educational Researchers, 18, 16-22.

24. Parla, J.A., (1994), "Educating teachers for cultural and linguistic diversity: A model for all teachers", New York State Association for Bilingual Education Journal, 9, 1-6.

25. Pettigrew, T. F., (1979), "Racial change and social policy", Annuals of the American Academy of Political and Social Sciences, 441, 114.

26. Pena, R. A., (1997), "Cultural differences and the construction of meaning: Implications for the leadership and organizational context of schools", Education Policy Analysis Archives, 5(10), 1-19. 
27. Penny, C. M., Forney, A., Harlee, T. M., (2000), "Issues challenging education. Preparing educators for multicultural classrooms", retrieved November 25, 1999 from http://www.horizon.unc.edu/projects/issies/ papers/Penny.asp.

28. Sanchez, W., (1995), "Working with diverse learners and school staff in a multicultural society", ERIC Clearinghouse American Psychological Association, Washington, DC, (ERIC Document Reproduction Service No. ED390018).

29. Schlosser, L. K., (1992), "Teacher distance and student disengagement: School lives on the margin", Journal of Teacher Education, 43(2), 128-140.

30. Tuckman, B. W., (1999), Conducting educational research, Fort Worth, Texas: Harcourt Brace College Publishers.

31. U.S. Department of Education., (1990), "Twelfth annual report to congress on the implementation of the Education of the Handicapped Act”, (ERIC Document Reproduction Service No. ED321513).

32. Wallace, K. R., (2001), "Incorporating multicultural/multiethnic topics in teacher preparation", Electronic Magazine of Multicultural Education, 3(2), 1-7, retrieved December 14, 2001 from http://www.eastern.edu/ publication/emme.

33. Zeichner, K. M., (1993), "Special Report: 16 Key Elements of Effective Teacher Education for Diversity", Educating teachers for cultural diversity (NCRTL special report), East Lansing, Michigan: National Center for Research on Teacher Learning,(ERIC Document Reproduction No. ED 359167).

\section{NOTES}


NOTES 